\title{
Ephedrine activates brown adipose tissue in lean but not obese humans
}

\author{
A. L. Carey • M. F. Formosa • B. Van Every • \\ D. Bertovic • N. Eikelis - G. W. Lambert • V. Kalff • \\ S. J. Duffy • M. H. Cherk • B. A. Kingwell
}

Received: 27 August 2012 / Accepted: 12 September 2012 /Published online: 13 October 2012

(C) Springer-Verlag Berlin Heidelberg 2012

\begin{abstract}
Aims/hypothesis Brown adipose tissue (BAT) activation increases energy consumption and may help in the treatment of obesity. Cold exposure is the main physiological stimulus for BAT thermogenesis and the sympathetic nervous system, which innervates BAT, is essential in this process. However, cold-induced BAT activation is impaired in obese humans. To explore the therapeutic potential of BAT, it is essential to determine whether pharmacological agents can activate BAT. Methods We aimed to determine whether BAT can be activated in lean and obese humans after acute administration of an orally bioavailable sympathomimetic. In a randomised, double-blinded, crossover trial, we administered $2.5 \mathrm{mg} / \mathrm{kg}$ of oral ephedrine to nine lean (BMI $22 \pm 1 \mathrm{~kg} / \mathrm{m}^{2}$ ) and nine obese (BMI $36 \pm 1 \mathrm{~kg} / \mathrm{m}^{2}$ ) young men. On a separate day, a placebo was administered to the same participants. BAT activity was assessed by measuring glucose uptake with $\left[{ }^{18} \mathrm{~F}\right]$ fluorodeoxyglucose and positron emission tomography-computed tomography imaging.
\end{abstract}

A. L. Carey $(\bowtie) \cdot$ M. F. Formosa $\cdot$ D. Bertovic $\cdot$ S. J. Duffy

B. A. Kingwell

Metabolic and Vascular Physiology Laboratory,

Baker IDI Heart and Diabetes Institute,

PO Box 6492, St Kilda Road Central,

Melbourne, VIC 8008, Australia

e-mail: andrew.carey@bakeridi.edu.au

N. Eikelis · G. W. Lambert

Human Neurotransmitters Laboratory,

Baker IDI Heart and Diabetes Institute,

Melbourne, VIC, Australia

B. Van Every $\cdot$ V. Kalff $\cdot$ M. H. Cherk

Department of Nuclear Medicine, Alfred Hospital,

Melbourne, VIC, Australia

D. Bertovic · S. J. Duffy · B. A. Kingwell

Department of Cardiology, Alfred Hospital,

Melbourne, VIC, Australia
Results BAT activity was increased by ephedrine compared with placebo in the lean, but unchanged in the obese, participants. The change in BAT activity after ephedrine compared with placebo was negatively correlated with various indices of body fatness.

Conclusions/interpretation BAT can be activated via acute, oral administration of the sympathomimetic ephedrine in lean, but not in obese humans.

Keywords Brown fat · Cold · Energy expenditure · Ephedrine $\cdot$ Noradrenaline (norepinephrine) .

Sympathomimetic - Thermogenesis - Type 2 diabetes Uncoupling protein $\cdot$ White fat

\begin{tabular}{|c|c|}
\hline \multicolumn{2}{|c|}{ Abbreviations } \\
\hline BAT & Brown adipose tissue \\
\hline FDG & {$\left[{ }^{18} \mathrm{~F}\right]$ fluorodeoxyglucose } \\
\hline $\mathrm{mSv}$ & Millisievert \\
\hline PET-CT & $\begin{array}{l}\text { Positron emission tomography-computerised } \\
\text { tomography }\end{array}$ \\
\hline SUV & Standardised uptake value \\
\hline SUVmax & Maximum SUV \\
\hline UCP-1 & Uncoupling protein 1 \\
\hline WAT & White adipose tissue \\
\hline
\end{tabular}

\section{Introduction}

It is well established that brown adipose tissue (BAT) has a central role in facultative and adaptive thermogenesis in rodents throughout their lifespan [1]. More recently, BAT has been conclusively identified and shown to be functional in adult humans [2-7]. BAT thermogenesis is underpinned by high energy consumption, suggesting that defective BAT may contribute causally to obesity and that BAT activation may have therapeutic potential for weight control $[8,9]$. 
These possibilities have been substantiated by rodent studies demonstrating that BAT contributes $\geq 50 \%$ of total glucose and triacylglycerol clearance after gavage feeding $[10,11]$ and $\sim 50 \%$ of adrenergically stimulated energy consumption above basal levels [12] in wild-type mice housed at room temperature. Furthermore, after prolonged cold exposure, BAT, via adaptive thermogenesis, is directly responsible for more than doubling whole-body energy expenditure [13].

Studies in the 1970s and 1980s provided circumstantial, but inconclusive evidence for the presence of functional BAT in adult humans [14, 15]. More recently, using positron emission tomography-computerised tomography (PET-CT) imaging with $\left[{ }^{18} \mathrm{~F}\right]$ fluorodeoxyglucose (FDG) tracer to measure tissue metabolic activity, it was found that an artefact infrequently observed in thoracic oncology scans was likely to be functional BAT $[3,16]$. Subsequent studies using acute cold exposure interventions and/or identification of BAT molecular markers in supraclavicular fat, irrefutably confirmed this tissue to be functional BAT [2, 4-7]. These and other studies also revealed that BAT is present in lean and obese adults, but that its volume and/or function, at least in response to cold, is reduced in obesity [4, 5, 17, 18].

With regard to the activation of BAT for weight control, a pharmacological approach has significant advantages over cold exposure, especially for long-term compliance. Repeated, prolonged cold exposure is impractical due to the associated discomfort and significant time commitment. Moreover, centrally derived signals that increase BAT activity and function in response to cold exposure are accompanied by increased appetite and food intake in an attempt to maintain energy balance [19]. An orally available pharmacological BAT activator devoid of appetite-stimulating effects could thus potentially help achieve sustainable weight loss.

In humans it is currently not known whether a pharmacological agent can activate BAT, as previous studies have used inconclusive experimental techniques $[9,20,21]$ or observed no effect of drugs on BAT activity [22, 23]. Since BAT activation is mediated by sympathetic efferents predominantly via $\beta$-adrenergic receptors in BAT [1], sympathomimetic drugs represent a relevant drug class for investigation. In contrast to physiological BAT activation via cold exposure, ephedrine increases noradrenaline (norepinephrine) in postsynaptic peripheral nerve terminals and does not act centrally to stimulate food intake [24]. The aims of the present study were therefore to determine whether a single dose of ephedrine can activate BAT in adult humans and whether this mechanism is defective in obesity.

\section{Methods}

Participants The participants in this study were nine lean and nine obese young men, who were otherwise healthy, unmedicated and physically inactive. The study was approved by the Alfred Hospital Ethics Committee. All patients provided written, informed consent.

Study design This study was a randomised, double-blinded, placebo-controlled, crossover trial, with 1 to 2 weeks wash-out between trials. Each participant was administered $2.5 \mathrm{mg} / \mathrm{kg}$ of the orally bioavailable sympathomimetic, ephedrine; an identical placebo was administered on a separate day. The study is registered with the Therapeutic Goods Administration of Australia (registration number 2010/0049) and ClinicalTrials.gov (registration number NCT01015794).

Since previous studies have indicated that BAT activity varies seasonally $[4,25]$, we conducted trials for each individual within a 14 day period to avoid confounding effects of intra-individual seasonal variation. The mean daily maximum temperature for the month prior to trials did not differ between groups (lean $20.5 \pm 1.6^{\circ} \mathrm{C}$; obese $20.6 \pm 1.6^{\circ} \mathrm{C}$ [mean $\pm \mathrm{SEM}$ ]) and there were no differences between the maximum temperature on the day before (lean group: placebo $23.1 \pm 2.1^{\circ} \mathrm{C}$, ephedrine $19.4 \pm 1.3^{\circ} \mathrm{C}$; obese group: placebo $21.4 \pm 2.1^{\circ} \mathrm{C}$, ephedrine $20.2 \pm 2.4^{\circ} \mathrm{C}$ ) or the minimum temperature on the night before (lean group: placebo $13.0 \pm 1.7^{\circ} \mathrm{C}$, ephedrine $9.5 \pm 1.5^{\circ} \mathrm{C}$; obese group: placebo $11.2 \pm 1.3^{\circ} \mathrm{C}$, ephedrine $10.4 \pm 1.8^{\circ} \mathrm{C}$ ) trials within or between groups. There were no correlations between the BAT activity observed during the trial and any temperature variables collected. Temperature information was obtained from the Australian Bureau of Meteorology (www.bom.gov.au; last accessed 1 Mar 2012).

Dose rationale We initially conducted (data not shown) studies in two participants (age 20 and 21 years, BMI 19.1 and $20.5 \mathrm{~kg} / \mathrm{m}^{2}$ ) who met the recruitment criteria (below). They were administered $1 \mathrm{mg} / \mathrm{kg}$ ephedrine, based on previous studies that documented significant physiological adrenergic responses (blood pressure and heart rate) at this dose $[20,26]$. No BAT activity was observed in these individuals despite changes in cardiovascular and metabolic responses being detected. Based on these pilot experiments, we hypothesised that BAT activation requires a greater ephedrine dose than other adrenergically responsive tissues. Subsequent experiments were thus conducted with an ephedrine dose of $2.5 \mathrm{mg} / \mathrm{kg}$, as described hereafter. Our limited pilot data are consistent with other comprehensive studies that were published during the preparation of this manuscript and clearly indicate that, in participants with cold-responsive BAT, a $1 \mathrm{mg} / \mathrm{kg}$ dose of ephedrine [22] or a dose of isoprenaline that induces similar physiological responses [23] is not sufficient to activate BAT.

Screening Screening involved clinical examination by a physician and measurement of physical characteristics (height, weight, WHR, brachial blood pressure, 12-lead 
ECG). A fasting blood sample was drawn for measurement of lipid profile, insulin, noradrenaline, $\mathrm{HbA}_{1 \mathrm{c}}$ and glucose. An OGTT (75 g glucose) was then performed. Body composition was measured using dual energy x-ray absorptiometry (DEXA). Participants were then randomly assigned to receive ephedrine or placebo on the first experimental day, followed 1 to 2 weeks later by the alternative intervention.

Experimental protocol Participants were given a standardised meal to consume the evening (between 18:00 and 22:00 hours) before attending the laboratory on both experimental days. The laboratory temperature was 20 to $22^{\circ} \mathrm{C}$ throughout all experiments. Upon arriving (07:3008:30 hours), having fasted overnight and abstained from exercise, caffeine, smoking and alcohol during the 2 previous days, participants voided and changed into hospital scrubs and socks. They swallowed a telemetric pill for continuous recording of core body temperature (Coretemp HQInc, Palmetto, FL, USA) and an indwelling venous cannula was inserted into an antecubital vein. Oscillometric brachial blood pressure (Suresigns VS3; Philips Medical Systems, Andover, MA, USA) was measured every $15 \mathrm{~min}$ and heart rate (Coretemp) continuously recorded. Participants rested in a supine position for $2 \mathrm{~h}$, while covered with two blankets to ensure a thermoneutral state.

After the rest period, a blood sample was taken and participants took either lactose (placebo) or $2.5 \mathrm{mg} / \mathrm{kg}$ ephedrine hydrochloride (ephedrine) in a gelatine capsule with $150 \mathrm{ml}$ of water. Blood samples were taken 15, 30, 60 and $90 \mathrm{~min}$ after drug ingestion for subsequent analyses (described below). At $60 \mathrm{~min}$ after drug ingestion, participants were injected with an FDG tracer to enable assessment of BAT glucose uptake via PET-CT. Energy expenditure was measured via indirect calorimetry (both described subsequently) from $\sim 60$ to 90 min after drug ingestion, the time predicted to correspond to peak plasma noradrenaline concentrations and BAT activity [20].

PET-CT imaging Between 60 and 70 min after drug or placebo ingestion, participants were injected with the FDG tracer. Approximately 60 min later, PET-CT scanning was performed to measure FDG uptake. Tracer uptake time was matched between trials for each participant. The CT scan is used for attenuation correction of PET images and to identify relevant adipose tissue regions for the assessment of FDG uptake. To minimise the radiation dose, we modified a standard PET-CT protocol commonly used for tumour detection. Weight-adjusted FDG (Cyclotek, Bundoora, VIC, Australia) was administered on the basis of an activity of 2.5 MBq/ $\mathrm{kg}$ up to a maximum of $185 \mathrm{MBq}$ with activity within $\pm 10 \%$ between scans. PET acquisition time was 6 min per bed position. Variables used for low-dose CT acquisition were: $140 \mathrm{kVp}$ (x-ray tube voltage), $20 \mathrm{~mA}, 1 \mathrm{~s}$ rotation,
$10 \mathrm{~mm}$ collimation width, 1.0 pitch and $37 \mathrm{~cm}$ scan length (from chin to diaphragm). Modified PET and CT variables resulted in an effective radiation dose of 4.9 millisievert $(\mathrm{mSv})$ per scan and have no bearing on subsequent standardised uptake value (SUV) calculations. The maximum radiation dose administered to participants was $10 \mathrm{mSv}$, which is the upper radiation limit permissible for healthy individuals over a 5 year period according to the Australian Code of Practice for Radiation in Research. PET-CT scans were acquired and reconstructed using a dual PET-CT scanner (Philips Gemini; Philips). Scans were analysed using $4 \mathrm{~mm}$ thick coronal slices (Extended Brilliance Workstation; Philips).

Analysis focused on the supraclavicular and cervical adipose tissue depots, as these areas have been consistently shown in numerous previous studies to demonstrate activity and/or molecular markers of BAT in humans [2, 4-7, 17, 18, 21-23, 27-31]. We used two criteria to identify active BAT. First, CT radiodensity had to be in the established range of -180 to -10 Hounsfield units for all adipose tissue analyses $[22,23,32]$. Second, we used a BAT-specific threshold to quantify tissue FDG uptake on PET scans by the SUV method. The SUV is the ratio of tissue radioactivity concentration and the injected activity divided by body weight, and is a semi-quantitative measure of tissue FDG uptake [33, 34].

We first quantified maximum SUV (SUVmax) after placebo and ephedrine treatments in supraclavicular and cervical adipose, subcutaneous adipose (upper arm) and skeletal muscle (lateral deltoid) tissue.

Second, we determined a threshold for SUV to define active BAT within regions corresponding to adipose tissue on CT (Hounsfield units -180 to -10 ). The supraclavicular and cervical adipose depots have recently been described as 'beige' adipose [31], i.e. tissue that may macroscopically resemble white adipose tissue (WAT), but has the capacity to develop some of the functional attributes of BAT in terms of metabolic activity. Thus, any tissue in this region demonstrating FDG uptake above that of WAT should be considered to be beige/brown fat in various stages of adaptation [31, 35]. SUVmax in subcutaneous WAT in the upper arm in all participants and under both trial conditions was $\leq 0.6 \mathrm{~g} / \mathrm{ml}(0.4 \pm$ 0.01 ; mean \pm SEM). On this basis we applied an SUV threshold for quantification of BAT volume/activity of $\geq 1.0 \mathrm{~g} / \mathrm{ml}$; while this might be considered low, it is consistent with previous studies reporting increased activity in BAT in this region [30, 36, 37]. Moreover, the preliminary analysis described above established that there was no overlap with WAT $[36,37]$. For this analysis we are also confident that this method did not include skeletal muscle, first because of the radiodensity criteria ( -180 to -10 Hounsfield units) and second because skeletal muscle SUVmax was $\leq 0.8 \mathrm{~g} / \mathrm{ml}$.

For each region of interest that met the $\mathrm{CT}$ and the PET criteria we multiplied the total volume $(\mathrm{ml})$ and the average SUV (mean SUV), then summed values for each region, 
which enabled the calculation of 'BAT activity' in the supraclavicular and cervical regions [22].

Indirect calorimetry Energy expenditure was measured with a metabolic measurement system (TrueOne 2400; ParvoMedics, East Sandy, UT, USA) using gas dilution with a ventilated hood. Mixed expired gases were measured after 10 min equilibration. Energy expenditure was calculated as an average over $30 \mathrm{~min}$.

Biochemical analyses Venous blood samples taken during screening and/or trials were centrifuged and plasma immediately frozen. Plasma was analysed for glucose, total cholesterol, HDL-cholesterol, LDL-cholesterol, triacylglycerol (enzymatic methods, automated analyser), insulin (chemiluminescent microparticle immunoassay) and $\mathrm{HbA}_{1 \mathrm{c}}$ (boronate-affinity HPLC) (all conducted according to clinical diagnostic standards by Alfred Hospital Pathology). Plasma NEFA were measured using a commercially available kit (Waco Diagnostics, Richmond, VA, USA). Plasma noradrenaline was extracted using alumina adsorption, separated by high-performance liquid chromatography and detected electrochemically as described [38].

Statistical analyses Physical characteristics were compared using unpaired two-tailed Student's $t$ tests. The response, in haemodynamics, temperature and circulating factors, to the interventions was assessed as the mean of measurements made at 60 to $90 \mathrm{~min}$ after ephedrine or placebo ingestion [20].

Repeated measures (treatment) ANOVA with group (lean/obese) and treatment order as between-subject factors was used to examine the effect of treatment (ephedrine, placebo). There were no significant effects of treatment order for any variable. Since PET-CT data were not normally distributed, non-parametric Wilcoxon's signed-rank tests were used. Regression analyses were performed using Pearson's correlation co-efficient. Analyses were conducted using SPSS (version 15; SPSS, Chicago, IL, USA) and Microsoft Excel (version 2007). Results are expressed as mean \pm SEM and were considered significant at $p<0.05$.

\section{Results}

Baseline participant characteristics are presented in Table 1. Groups were matched for age and height, but the obese group had significantly higher BMI, WHR, and absolute and relative body fat mass than lean participants. Lean tissue mass was also slightly higher in the obese than in the lean group, but was significantly lower as a percentage of body mass. Both groups were normotensive and had similar blood pressure, heart rate and circulating noradrenaline. Fasting glucose and $\mathrm{HbA}_{1 \mathrm{c}}$ were in the normal range and not
Table 1 Participant characteristics

\begin{tabular}{|c|c|c|c|}
\hline Variable & Lean & Obese & $p$ value \\
\hline$n$ & 9 & 9 & \\
\hline \multicolumn{4}{|l|}{ Physical characteristics } \\
\hline Age (years) & $25 \pm 1$ & $27 \pm 1$ & 0.22 \\
\hline Height $(\mathrm{cm})$ & $176 \pm 3$ & $178 \pm 2$ & 0.50 \\
\hline Weight (kg) & $68 \pm 2$ & $115 \pm 5$ & $<0.001$ \\
\hline BMI $\left(\mathrm{kg} / \mathrm{m}^{2}\right)$ & $22 \pm 1$ & $36 \pm 1$ & $<0.001$ \\
\hline Body fat $(\%)$ & $17 \pm 2$ & $44 \pm 2$ & $<0.001$ \\
\hline Body fat $(\mathrm{kg})$ & $11 \pm 1$ & $49 \pm 4$ & $<0.001$ \\
\hline Body lean tissue (kg) & $54 \pm 2$ & $61 \pm 2$ & 0.048 \\
\hline Body lean tissue (\%) & $82 \pm 2$ & $56 \pm 2$ & $<0.001$ \\
\hline WHR & $0.83 \pm 0.01$ & $0.93 \pm 0.02$ & $<0.001$ \\
\hline \multicolumn{4}{|l|}{ Cardiovascular $^{\mathrm{a}}$} \\
\hline Systolic BP (mmHg) & $114 \pm 3$ & $119 \pm 2$ & 0.22 \\
\hline Diastolic BP (mmHg) & $72 \pm 2$ & $71 \pm 2$ & 0.84 \\
\hline Heart rate $(\mathrm{bpm})$ & $64 \pm 2$ & $69 \pm 3$ & 0.18 \\
\hline \multicolumn{4}{|l|}{ Hormones, metabolites, lipids ${ }^{\mathrm{b}}$} \\
\hline Noradrenaline (pmol/l) & $1036 \pm 135$ & $1173 \pm 208$ & 0.59 \\
\hline Insulin $(\mathrm{pmol} / \mathrm{l})$ & $36 \pm 7$ & $88 \pm 14$ & 0.01 \\
\hline Glucose (mmol/l) & $5.0 \pm 0.1$ & $5.1 \pm 0.2$ & 0.60 \\
\hline $\mathrm{HbA}_{1 \mathrm{c}}(\%)$ & $5.5 \pm 0.1$ & $5.5 \pm 0.1$ & 0.92 \\
\hline $\mathrm{HbA}_{1 \mathrm{c}}(\mathrm{mmol} / \mathrm{mol})$ & $36.6 \pm 0.9$ & $36.7 \pm 0.9$ & 0.92 \\
\hline Total cholesterol $(\mathrm{mmol} / \mathrm{l})$ & $4.2 \pm 0.2$ & $4.7 \pm 0.2$ & 0.04 \\
\hline HDL-cholesterol (mmol/l) & $1.4 \pm 0.1$ & $1.0 \pm 0.1$ & 0.01 \\
\hline LDL-cholesterol (mmol/1) & $2.5 \pm 0.2$ & $3.1 \pm 0.2$ & 0.03 \\
\hline Triacylglycerol (mmol/l) & $0.7 \pm 0.1$ & $1.3 \pm 0.2$ & 0.01 \\
\hline NEFA $(\mu \mathrm{mol} / 1)$ & $288 \pm 26$ & $398 \pm 44$ & 0.048 \\
\hline \multicolumn{4}{|l|}{ OGTT } \\
\hline $60 \mathrm{~min}$ glucose $(\mathrm{mmol} / \mathrm{l})$ & $5.8 \pm 0.4$ & $7.5 \pm 0.6$ & 0.03 \\
\hline $120 \mathrm{~min}$ glucose $(\mathrm{mmol} / \mathrm{l})$ & $4.5 \pm 0.3$ & $5.9 \pm 0.4$ & 0.01 \\
\hline
\end{tabular}

Values are mean \pm SEM

${ }^{\text {a }}$ Resting values

${ }^{\mathrm{b}}$ Fasting circulating values

different between groups. The fasting insulin concentration was significantly higher in the obese than in the lean group, as were glucose concentrations at 60 and $120 \mathrm{~min}$ of the OGTT. Compared with lean participants, total and LDLcholesterol, triacylglycerol and NEFA were higher in the obese group. HDL-cholesterol was lower in the latter.

Ephedrine increased systolic blood pressure $(p<0.001)$ (Fig. 1a, b) and heart rate $(p=0.01)$ (Fig. 1e, f) by a similar magnitude in both groups. Diastolic blood pressure increased significantly in lean $(p=0.001)$, but not in obese participants $(p<0.05$ for treatment $\times$ group interaction) (Fig. 1c, d). Ephedrine had no effect on core temperature in either group, with the change from baseline to the mean of data points between 60 and $90 \mathrm{~min}$ after treatments being as follows: lean group, placebo $0.03 \pm 0.06^{\circ} \mathrm{C}$, ephedrine $0.08 \pm 0.06^{\circ} \mathrm{C}$; obese group, 

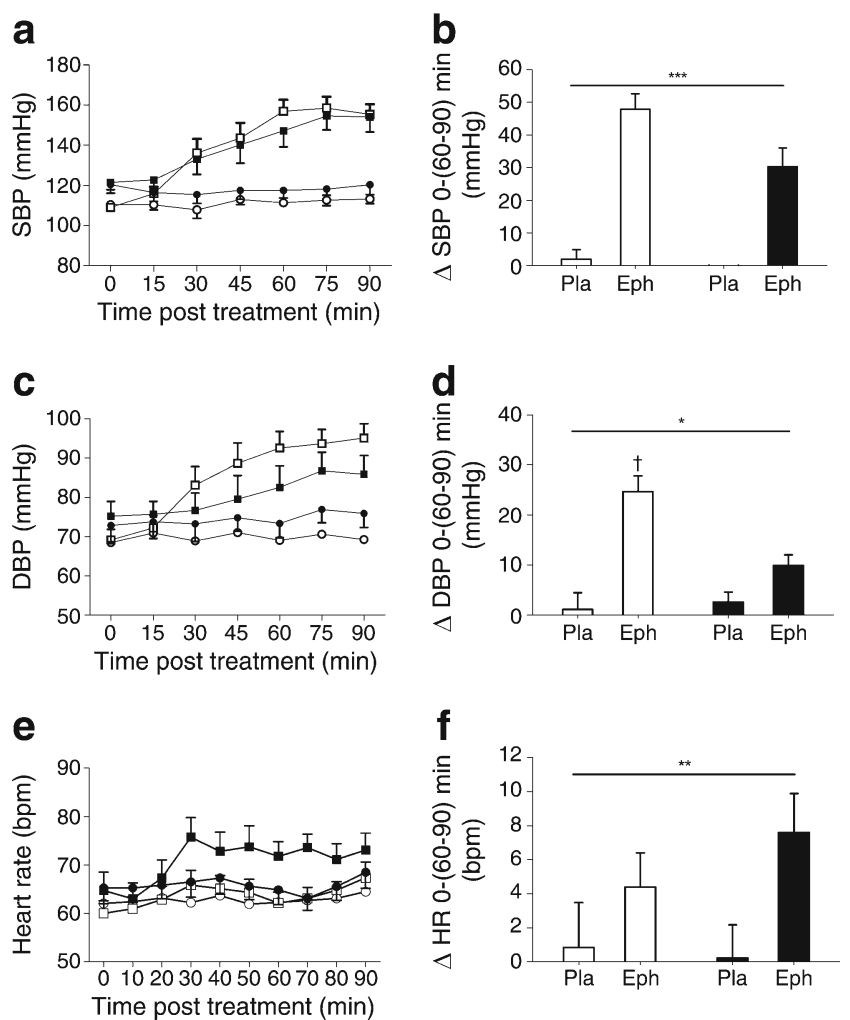

Fig. 1 (a) Time course of systolic BP (SBP), (c) diastolic BP (DBP) and (e) heart rate before and after treatment with a single dose of ephedrine $(2.5 \mathrm{mg} / \mathrm{kg}$ ) or placebo (lactose). White circles, lean placebo; black circles, obese placebo; white squares, lean ephedrine; black squares, obese ephedrine. (b) Changes $(\Delta)$ in SBP, (d) DBP and (f) heart rate $(\mathrm{HR})$ from immediately prior $(0 \mathrm{~min})$ to ingestion of ephedrine $(\mathrm{Eph})$ or placebo $(\mathrm{Pla})$ to the mean of values taken between 60 and 90 min after ingestion of treatments. White bars, lean group; black bars, obese group. Lean group $n=9$; obese group, $n=9 ;{ }^{*} p<0.05$ for treatment $\times$ group interaction; $* * p=0.01$ and $* * * p<0.001$ for main effect of treatment; ${ }^{\dagger} p=0.001$ for greater effect of ephedrine than placebo in lean group

placebo $0.02 \pm 0.03^{\circ} \mathrm{C}$, ephedrine $0.03 \pm 0.13^{\circ} \mathrm{C}$. Ephedrine increased energy expenditure by a similar magnitude in both groups (lean $18 \pm 3 \%$, obese $13 \pm 2 \% ; p<0.001$ ).

Ephedrine increased blood glucose $(p<0.001)$ (Fig. 2a, b) and plasma noradrenaline $(p<0.001)$ (Fig. 2c, d) similarly in both groups. The plasma NEFA concentration was unchanged with ephedrine in both groups (Fig. 2e, f).

Ephedrine increased supraclavicular adipose SUVmax by $145 \pm 48 \%$ in lean participants $(p<0.05)$ (Fig. 3a), but there was no change in the obese group $(4.0 \pm 8.3 \%)$. Similarly, BAT activity was undetectable after placebo treatment and increased to $27.1 \pm 12.1 \mathrm{ml} \times \mathrm{g} / \mathrm{ml}$ after ephedrine treatment in lean participants $(p<0.05)$ (Fig. 3c), but there was no effect in the obese group (placebo $8.7 \pm 6.3 \mathrm{ml} \times \mathrm{g} / \mathrm{ml}$, ephedrine 8.8 $\pm 8.8 \mathrm{ml} \times \mathrm{g} / \mathrm{ml}$ ). In lean participants treated with ephedrine, SUVmax was higher in seven of nine individuals, while BAT activity increased in six of nine individuals. Post-ephedrine PET images showing FDG uptake are shown in Fig. 3d. a

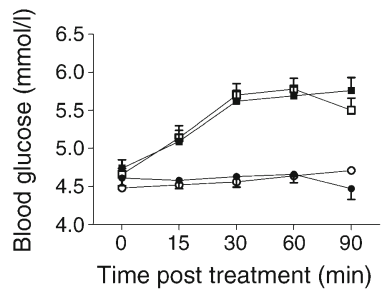

b
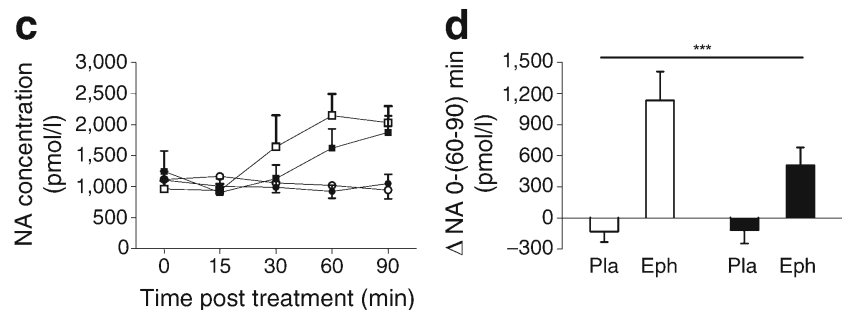

e
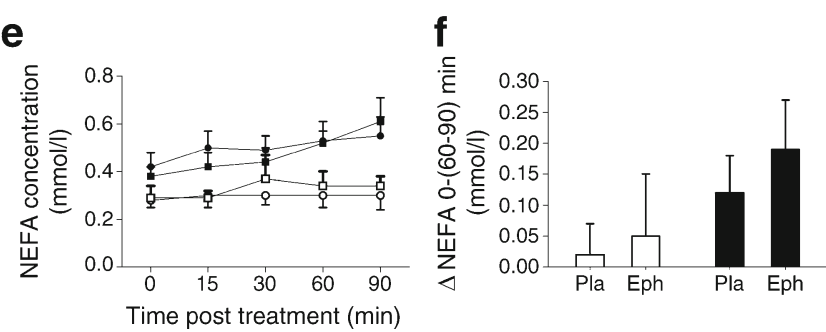

Fig. 2 (a) Time course of blood glucose, (c) plasma noradrenaline (NA) and (e) plasma NEFA concentrations before and after treatment with a single dose of ephedrine $(2.5 \mathrm{mg} / \mathrm{kg}$ ) or placebo (lactose). White circles, lean placebo; black circles, obese placebo; white squares, lean ephedrine; black squares, obese ephedrine. (b) Changes $(\Delta)$ in blood glucose, (d) plasma NA and (f) plasma NEFA concentrations from immediately prior $(0 \mathrm{~min})$ to ingestion of ephedrine $(\mathrm{Eph})$ or placebo (Pla) to the mean of values taken between 60 and 90 min after ingestion of treatments. White bars, lean group; black bars, obese group. Lean group, $n=9$; obese group, $n=9$; $* * * p<0.001$ for main effect of treatment

Subcutaneous WAT SUVmax was similar for all groups and conditions (Fig. 3b).

While BAT activity was not present under placebo conditions in any of the lean participants, it was observed in two obese participants after placebo. However, there was no between-groups difference in supraclavicular adipose SUVmax or BAT activity in the placebo trials (Fig. 3a, c).

The change in BAT SUVmax and BAT activity after ephedrine compared with placebo was inversely correlated $(p \leq 0.05)$ with a number of indices of body fat content and size (Table 2). No other relationships were observed between BAT SUVmax or activity and other variables (e.g. energy expenditure, acute or prolonged environmental temperature prior to trials, circulating metabolites and hormones, lean body mass).

\section{Discussion}

We report for the first time that the sympathomimetic drug ephedrine activates BAT in the majority of lean, but not obese 
a

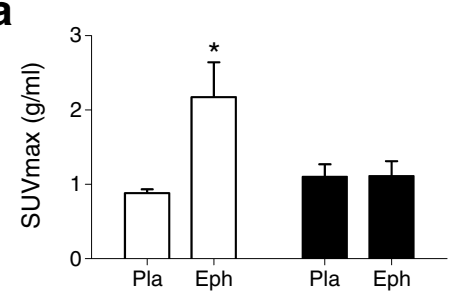

b

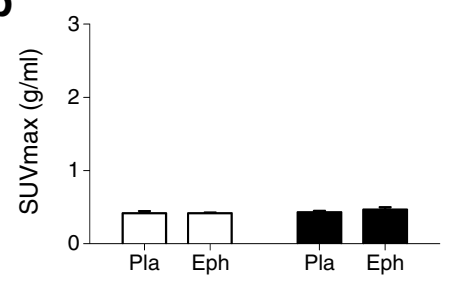

C

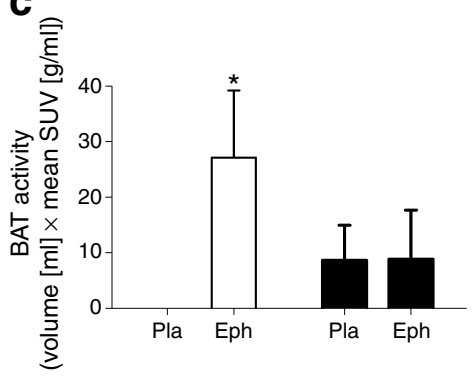

Fig. 3 (a) Supraclavicular-cervical and (b) subcutaneous adipose SUVmax, and (c) BAT activity measured after treatment with a single dose of ephedrine (2.5 mg/kg) (Eph) or placebo (lactose) (Pla). White bars, lean group; black bars, obese group. (d) Representative images of three-dimensional reconstructed images for each participant after ephedrine trials. Note, the last lean participant has dextrocardia. Lean group, $n=9$; obese group, $n=9 ;{ }^{*} p<0.05$ for difference from placebo

individuals. This observation provides proof-of-concept support for the notion that pharmacological activation of BAT in humans is possible. The failure of ephedrine to acutely activate BAT in obese individuals also raises the possibility of a causal relationship between inactive BAT and obesity, although it cannot be determined from our results whether defective BAT contributes to obesity or vice-versa.

BAT can be activated pharmacologically in lean humans Our aim was not to advocate ephedrine as a clinical intervention,

Table 2 Relationship between body fatness/size and BAT activity

\begin{tabular}{lcc}
\hline Variable & $\Delta$ SUVmax $r(p)$ & $\Delta$ BAT activity $r(p)$ \\
\hline BMI & $-0.53(0.024)$ & $-0.47(0.047)$ \\
\% Body fat & $-0.52(0.027)$ & $-0.46(0.054)$ \\
Total body fat $(\mathrm{kg})$ & $-0.53(0.023)$ & $-0.47(0.050)$ \\
Total body mass $(\mathrm{kg})$ & $-0.55(0.019)$ & $-0.48(0.051)$ \\
\hline
\end{tabular}

Correlation coefficients $(r)$ and $p$ values $(p)$ between the change (ephedrine-placebo) in SUVmax or BAT activity and variables as listed Lean participants, $n=9$; obese participants, $n=9$ but rather to use it to successfully demonstrate that pharmacological BAT activation is possible in humans. The principal mechanism of action of ephedrine is via displacement and release of noradrenaline from storage vesicles in presynaptic neurons, but it also has direct effects on peripheral adrenergic receptors [24]. In lean participants, circulating noradrenaline approximately doubled after ephedrine compared with placebo administration, which presumably resulted in much higher concentrations in target tissues. This was associated with a $\sim 2.5$-fold increase in SUVmax and a significant increase in BAT activity.

The 2.5-fold increase in SUVmax after ephedrine treatment in the lean group was considerably smaller than the more than fourfold increases observed after acute cold treatments in similar lean cohorts $[6,22]$. This is further demonstrated by the level of BAT activity in the present study $(27 \mathrm{ml} \times \mathrm{g} / \mathrm{ml}$ after $2.5 \mathrm{mg} / \mathrm{kg}$ ephedrine), compared with that reported by Cypess et al after cold exposure $(\sim 110 \mathrm{ml} \times \mathrm{g} / \mathrm{ml})$ in a cohort of comparable participants [22]. A possible explanation for this difference in the effect of cold and ephedrine on BAT activity is the specificity of the stimulus. Cold exposure provides a sympathetic stimulus targeted to relevant adrenergic receptors within BAT, whereas systemic ephedrine administration is not targeted directly to BAT $[39,40]$. Thus systemic ephedrine administration will not specifically raise noradrenaline in the region of BAT adrenergic receptors and it is likely that relatively high plasma noradrenaline would be required to activate BAT in humans. This concept is well supported by our pilot data (not shown) and a recent publication [22], which both demonstrate that a lower dose of ephedrine $(1 \mathrm{mg} / \mathrm{kg})$ than that used in our main study $(2.5 \mathrm{mg} / \mathrm{kg})$ does not activate BAT. It has also been recently shown that isoprenaline does not activate BAT [23]. Moreover, the increase in noradrenaline and systolic blood pressure in all three instances was similar, despite the differences in route of administration, including oral (our pilot data), intramuscular [22] or intravenous [23]. In contrast to the above, our higher dose of ephedrine $(2.5 \mathrm{mg} / \mathrm{kg})$ induced a greater change in systolic blood pressure $(\sim 45 \mathrm{mmHg}$ vs $\sim 25 \mathrm{mmHg}$ in the three other experiments) and increased plasma noradrenaline by a similar amount to that achieved by cold exposure [22], while both activated BAT, albeit by differing magnitudes. This suggests that, with regard to systemic sympathomimetic activation of BAT, it is the increase in plasma noradrenaline concentration, rather than the route of administration that is important. Our data highlight the poor responsiveness of BAT to systemic adrenergic stimulation compared with that of the cardiovascular system, but nevertheless show that BAT does retain some capacity to be activated via this method.

In rodents, BAT activation and increased energy expenditure in response to cold and sympathomimetic drugs is of considerably greater magnitude than in humans. Furthermore, BAT activation occurs in all rodents in response to 
these stimuli, whereas many humans, particularly the obese, are unresponsive. In the present study, energy expenditure increased by $18 \%$ in lean participants after ephedrine. This is in agreement with previous human studies, where cold exposure, ephedrine ingestion and noradrenaline infusion increased energy expenditure by between 5 and 30\% [5, $20,41-45]$, with BAT contributing around 1 to $5 \%$ to the elevation of energy expenditure above basal levels during cold exposure $[28,46]$. In contrast, acute cold exposure or noradrenaline injection increased energy expenditure in mice by $100 \%$ [13]. Moreover, chronic adaptive cold thermogenesis in mice increased noradrenaline-stimulated energy expenditure approximately by an additional $100 \%$ [13], whereas in humans the additional increase was only about $15 \%$ [42].

BAT activation in humans varies considerably after cold, both in terms of the proportion of responsive individuals and the magnitude of response. In previous studies, between 50 and $100 \%$ of young lean adult males showed some response to cold $[4-6,28,29]$. This is consistent with our observations for ephedrine treatment here. The variation in the proportion of individuals responsive to cold may be due to differences in cooling protocols or analytical techniques, including the criteria used to classify BAT as active. Similarly, drug delivery protocols and especially dose are likely to influence the proportion of individuals in whom BAT can be activated. It is not known whether stronger stimuli can lead to BAT activation in all healthy, young lean individuals.

We observed no correlation between change in BAT activity after ephedrine and the increase in energy expenditure $[5,34]$. Unlike in rodents, the majority of sympathomimeticinduced increases in energy expenditure in humans can probably be explained by increases in metabolic activity in tissues other than BAT, with skeletal muscle likely to be the major contributor $[20,46]$. While cold-induced BAT activity correlates with energy expenditure [5, 28, 29, 34], the lesser degree of BAT activation detected here suggests that ephedrineinduced BAT activity makes only a small contribution to energy expenditure, possibly less than the value of $\sim 1 \%$ reported recently after cold exposure [28]. The current finding that ephedrine induced similar increases in whole-body energy expenditure in lean and obese participants, despite BAT activation occurring only in the former, is consistent with this.

Sympathomimetic-induced BAT activity is impaired in human obesity No increase in BAT activity was seen in response to ephedrine in the obese group. This is consistent with cold exposure studies, where no or low proportions of obese individuals exhibited BAT activation [4, 5, 18]. Importantly, to establish dose equivalence in the lean and obese groups, ephedrine was delivered as a weight-adjusted dose and induced similar physiological responses in both groups (systolic blood pressure, plasma noradrenaline and blood glucose). It is not presently known whether: (1) the defect in BAT activation in obesity relates to a defect in one or a combination of factors, including adrenergic receptor signal transduction in brown adipocytes; or (2) abnormalities exist in relevant afferent or efferent neural pathways; or (3) BAT is completely absent in most obese individuals.

Therapeutic implications We have established that it is possible to acutely activate BAT with ephedrine. From a therapeutic perspective, a pan-adrenergic agonist such as ephedrine is not sufficiently targeted for clinical use. An alternative approach could involve interventions to sensitise BAT (akin to adaptive thermogenesis) and thus improve its function. At present, it is not known whether human BAT can undergo adaptive thermogenesis as observed in rodents. Indeed, there is no clear evidence to indicate whether it is at all possible to increase adult BAT function, whether by chronic cold exposure, diet-induced adaptive thermogenesis or a pharmacological agent. Joy [42] and Astrup et al [26] demonstrated in humans that chronic cold and ephedrine ingestion, respectively, increased acute noradrenaline infusion-induced energy expenditure. Moreover, shivering decreases during cold exposure after $\sim 2$ weeks [47] and cold-stimulated activity has been shown to vary seasonally [4]. However, it remains unknown whether all or a portion of these effects can be directly attributed to adaptive BAT thermogenesis [48].

A more experimental strategy for BAT therapeutics is the induction of brown/brown-like adipocytes within WAT [35, 49]. Indeed, a recently published study suggests that, in humans, BAT tissue may be 'beige' adipose tissue. This corresponds in mice to a type of fat that contains mixed cell types, thus consisting not of classical BAT cells, but of adipocytes that resemble white adipocytes histologically, yet have the capacity to induce uncoupling protein 1 (UCP-1) and function as BAT cells [31]. UCP-1 gene expression and protein content are important markers of a BAT-like transition in WAT. When the activity of UCP-1 is increased, cellular substrate oxidation is increased by uncoupling the transport of hydrogen ions from ATP resynthesis across the mitochondrial inner membrane. In rodent models, ectopic production of UCP-1 protein in WAT, rather than in typical BAT depots, may be more important in protecting from obesity [49]. In humans, the BAT depots identified by PET-CT are presumed to be of sufficient size to impact on basal energy expenditure, if maximally activated $[6,9]$. However, given the relatively low BAT:WAT ratio in humans compared with rodents, and with evidence that beige adipocytes are present in humans [31], the possibility of inducing brown or brown-like adipocyte activity in WAT should be investigated.

Conclusions and perspectives We have demonstrated for the first time that BAT can be activated in the majority of lean, but not in obese humans with a single dose of ephedrine, although 
the degree of activation is substantially lower than that observed for cold exposure. This finding is important with regard to the future development of therapeutics targeting obesity. BAT activation strategies could operate alone and in concert with conventional weight loss strategies to improve sustainability. For example, if BAT could be induced to chronically increase basal energy expenditure, this could partially offset the reduction of basal energy expenditure observed with conventional lifestyle-oriented weight loss approaches [50]. Regardless of whether defective BAT is a cause or consequence of obesity, it remains a potential therapeutic target in individuals with established obesity. From this angle, the most important question is whether BAT function can be enhanced in a specific manner, such that chronic stimulation could increase the basal metabolic rate.

Acknowledgements We would like to thank the research participants for their time and interest in our study.

Funding This study was supported by the National Heart and Medical Research Council of Australia, the Alan Williams Trust and the Operational Infrastructure Support (OIS) Scheme of the Victorian State Government.

Duality of interest The authors declare that there is no duality of interest associated with this manuscript.

Contribution statement ALC conceived the study, conducted research trials, data collection and analysis, and wrote the manuscript. MFF recruited and screened participants, conducted data collection and reviewed/edited the manuscript. BVE designed the PET scanning protocol, assisted research trials, conducted data analysis and reviewed/ edited the manuscript. DB was involved in the conception of study design, conducted medical screening of participants and research trials, and reviewed/edited the manuscript. NE conducted data analyses, assisted with manuscript preparation and reviewed/edited the manuscript. GWL was involved in the conception of the study design and data analyses, and reviewed/edited the manuscript. VK was involved in the conception of the study design and the PET scanning protocol, and reviewed/edited the manuscript. SJD was involved in the conception of the study design, conducted medical screening of participants and research trials, and reviewed/edited the manuscript. MHC was involved in the conception of the study design, designed the PET scanning protocol, assisted with research trials and reviewed/edited the manuscript. BAK conceived and directed the study, conducted data analysis and wrote/edited the manuscript. All authors have approved this version of the manuscript.

\section{References}

1. Cannon B, Nedergaard J (2004) Brown adipose tissue: function and physiological significance. Physiol Rev 84:277-359

2. Cypess AM, Lehman S, Williams G et al (2009) Identification and importance of brown adipose tissue in adult humans. N Engl J Med $360: 1509-1517$
3. Nedergaard J, Bengtsson T, Cannon B (2007) Unexpected evidence for active brown adipose tissue in adult humans. Am $\mathrm{J}$ Physiol Endocrinol Metab 293:E444-E452

4. Saito M, Okamatsu-Ogura Y, Matsushita M et al (2009) High incidence of metabolically active brown adipose tissue in healthy adult humans: effects of cold exposure and adiposity. Diabetes 58:1526-1531

5. van Marken Lichtenbelt WD, Vanhommerig JW, Smulders NM et al (2009) Cold-activated brown adipose tissue in healthy men. N Engl J Med 360:1500-1508

6. Virtanen KA, Lidell ME, Orava J et al (2009) Functional brown adipose tissue in healthy adults. N Engl J Med 360:1518-1525

7. Zingaretti MC, Crosta F, Vitali A et al (2009) The presence of UCP1 demonstrates that metabolically active adipose tissue in the neck of adult humans truly represents brown adipose tissue. FASEB J 23:3113-3120

8. Himms-Hagen J (1979) Obesity may be due to a malfunctioning of brown fat. Can Med Assoc J 121:1361-1364

9. Rothwell NJ, Stock MJ (1979) A role for brown adipose tissue in diet-induced thermogenesis. Nature 281:31-35

10. Bartelt A, Bruns OT, Reimer R et al (2011) Brown adipose tissue activity controls triglyceride clearance. Nat Med 17:200-205

11. Nedergaard J, Bengtsson T, Cannon B (2011) New powers of brown fat: fighting the metabolic syndrome. Cell Metab 13:238240

12. Feldmann HM, Golozoubova V, Cannon B, Nedergaard J (2009) UCP1 ablation induces obesity and abolishes diet-induced thermogenesis in mice exempt from thermal stress by living at thermoneutrality. Cell Metab 9:203-209

13. Golozoubova V, Cannon B, Nedergaard J (2006) UCP1 is essential for adaptive adrenergic nonshivering thermogenesis. Am J Physiol Endocrinol Metab 291:E350-E357

14. Huttunen P, Hirvonen J, Kinnula V (1981) The occurrence of brown adipose tissue in outdoor workers. Eur J Appl Physiol Occup Physiol 46:339-345

15. Kang BS, Han DS, Paik KS et al (1970) Calorigenic action of norepinephrine in the Korean women divers. J Appl Physiol 29:6-9

16. Hany TF, Gharehpapagh E, Kamel EM, Buck A, Himms-Hagen J, von Schulthess GK (2002) Brown adipose tissue: a factor to consider in symmetrical tracer uptake in the neck and upper chest region. Eur J Nucl Med Mol Imaging 29:1393-1398

17. Lee P, Zhao JT, Swarbrick MM et al (2011) High prevalence of brown adipose tissue in adult humans. J Clin Endocrinol Metab 96:2450-2455

18. Vijgen GH, Bouvy ND, Teule GJ, Brans B, Schrauwen P, van Marken Lichtenbelt WD (2011) Brown adipose tissue in morbidly obese subjects. PLoS One 6:e17247

19. Rothwell NJ, Stock MJ (1979) Regulation of energy balance in two models of reversible obesity in the rat. J Comp Physiol Psychol 93:1024-1034

20. Astrup A, Bulow J, Madsen J, Christensen NJ (1985) Contribution of BAT and skeletal muscle to thermogenesis induced by ephedrine in man. Am J Physiol 248:E507-E515

21. Yoneshiro T, Aita S, Kawai Y, Iwanaga T, Saito M (2012) Nonpungent capsaicin analogs (capsinoids) increase energy expenditure through the activation of brown adipose tissue in humans. Am J Clin Nutr 95:845-850

22. Cypess AM, Chen YC, Sze C et al (2012) Cold but not sympathomimetics activates human brown adipose tissue in vivo. Proc Natl Acad Sci USA 109:10001-10005

23. Vosselman MJ, van der Lans AA, Brans B, et al (2012) Systemic beta-adrenergic stimulation of thermogenesis is not accompanied by brown adipose tissue activity in humans. Diabetes (in press)

24. Dulloo AG, Seydoux J, Girardier L (1991) Peripheral mechanisms of thermogenesis induced by ephedrine and caffeine in brown adipose tissue. Int J Obes 15:317-326 
25. Ouellet V, Routhier-Labadie A, Bellemare W et al (2011) Outdoor temperature, age, sex, body mass index, and diabetic status determine the prevalence, mass, and glucose-uptake activity of 18F-FDGdetected BAT in humans. J Clin Endocrinol Metab 96:192-199

26. Astrup A, Lundsgaard C, Madsen J, Christensen NJ (1985) Enhanced thermogenic responsiveness during chronic ephedrine treatment in man. Am J Clin Nutr 42:83-94

27. Yoneshiro T, Aita S, Matsushita M et al (2011) Age-related decrease in cold-activated brown adipose tissue and accumulation of body fat in healthy humans. Obesity (Silver Spring) 19:1755-1760

28. Muzik O, Mangner TJ, Granneman JG (2012) Assessment of oxidative metabolism in brown fat using PET imaging. Front Endocrinol (Lausanne) 3:15

29. Orava J, Nuutila P, Lidell ME et al (2011) Different metabolic responses of human brown adipose tissue to activation by cold and insulin. Cell Metab 14:272-279

30. Ouellet V, Labbe SM, Blondin DP et al (2012) Brown adipose tissue oxidative metabolism contributes to energy expenditure during acute cold exposure in humans. J Clin Invest 122:545-552

31. Wu J, Bostrom P, Sparks LM et al (2012) Beige adipocytes are a distinct type of thermogenic fat cell in mouse and human. Cell 150:366-376

32. Torriani M, Fitch K, Stavrou E et al (2012) Deiodinase 2 expression is increased in dorsocervical fat of patients with HIV-associated lipohypertrophy syndrome. J Clin Endocrinol Metab 97:E602-E607

33. Alkhawaldeh K, Alavi A (2008) Quantitative assessment of FDG uptake in brown fat using standardized uptake value and dual-timepoint scanning. Clin Nucl Med 33:663-667

34. Yoneshiro T, Aita S, Matsushita M et al (2010) Brown adipose tissue, whole-body energy expenditure, and thermogenesis in healthy adult men. Obesity (Silver Spring) 19:13-16

35. Petrovic N, Walden TB, Shabalina IG, Timmons JA, Cannon B, Nedergaard J (2010) Chronic peroxisome proliferator-activated receptor gamma (PPARgamma) activation of epididymally derived white adipocyte cultures reveals a population of thermogenically competent, UCP1-containing adipocytes molecularly distinct from classic brown adipocytes. J Biol Chem 285:7153-7164

36. Baba S, Tatsumi M, Ishimori T, Lilien DL, Engles JM, Wahl RL (2007) Effect of nicotine and ephedrine on the accumulation of 18F-FDG in brown adipose tissue. J Nucl Med 48:981-986
37. Ponrartana S, Aggabao PC, Hu HH, Aldrovandi GM, Wren TA, Gilsanz V (2012) Brown adipose tissue and its relationship to bone structure in pediatric patients. J Clin Endocrinol Metab 97:26932698

38. Lambert GW, Jonsdottir IH (1998) Influence of voluntary exercise on hypothalamic norepinephrine. J Appl Physiol 85:962-966

39. Astrup A, Bulow J, Christensen NJ, Madsen J (1984) Ephedrineinduced thermogenesis in man: no role for interscapular brown adipose tissue. Clin Sci (Lond) 66:179-186

40. Becker DE (1992) Clinical implications of autonomic drugs. J Oral Maxillofac Surg 50:734-740

41. Jessen K, Rabol A, Winkler K (1980) Total body and splanchnic thermogenesis in curarized man during a short exposure to cold. Acta Anaesthesiol Scand 24:339-344

42. Joy RJ (1963) Responses of cold-acclimatized men to infused norepinephrine. J Appl Physiol 18:1209-1212

43. Napolitano A, Murgatroyd PR, Finer N, et al (2011) Assessment of acute and chronic pharmacological effects on energy expenditure and macronutrient oxidation in humans: responses to ephedrine. J Obes (in press)

44. Shannon JR, Gottesdiener K, Jordan J et al (1999) Acute effect of ephedrine on 24-h energy balance. Clin Sci (Lond) 96:483-491

45. Sjostrom L, Schutz Y, Gudinchet F, Hegnell L, Pittet PG, Jequier E (1983) Epinephrine sensitivity with respect to metabolic rate and other variables in women. Am J Physiol 245:E431-E442

46. van Marken Lichtenbelt WD, Schrauwen P (2011) Implications of nonshivering thermogenesis for energy balance regulation in humans. Am J Physiol Regul Integr Comp Physiol 301:R285R296

47. Davis TR (1961) Chamber cold acclimatization in man. J Appl Physiol 16:1011-1015

48. Cannon B, Nedergaard J (2010) Metabolic consequences of the presence or absence of the thermogenic capacity of brown adipose tissue in mice (and probably in humans). Int J Obes (Lond) 34 (Suppl 1):S7-S16

49. Kozak LP, Koza RA (2011) The genetics of brown adipose tissue. Prog Mol Biol Transl Sci 94:75-123

50. Leibel RL, Rosenbaum M, Hirsch J (1995) Changes in energy expenditure resulting from altered body weight. N Engl J Med 332:621-628 